\title{
Risk Factors for Dislocation After Revision Total Hip Arthroplasty
}

\author{
Nathan G. Wetters BS, Trevor G. Murray MD, \\ Mario Moric MS, Scott M. Sporer MD, \\ Wayne G. Paprosky MD, Craig J. Della Valle MD
}

Published online: 7 September 2012

(C) The Association of Bone and Joint Surgeons (B) 2012

\begin{abstract}
Background Despite dislocation being the most frequent complication after revision THA, risk factors for its occurrence are not completely understood.

Questions/purposes We therefore (1) determined the overall risk of dislocation after revision THA in a large series of revision THAs using contemporary revision techniques, (2) identified patient-related risk factors predicting dislocation, and (3) identified surgical variables predicting dislocation.

Methods We performed 1211 revision THAs between June 2004 and October 2010 in 576 women and 415 men who had a mean age of 64.7 years (range, $25-95$ years) at
\end{abstract}

The institution of one or more of the authors (SMS, WGP, CJDV) has received, during the study period, funding from Zimmer Inc (Warsaw, IN, USA), Smith \& Nephew Inc (Memphis, TN, USA), and Stryker Orthopaedics (Mahwah, NJ, USA).

One of the authors (TGM) certifies that he, or a member of his immediate family, has received or may receive payments or benefits, during the study period, an amount of less than $\$ 10,000$, from Zimmer Inc. One of the authors (SMS) certifies that he, or a member of his immediate family, has received or may receive payments or benefits, during the study period, an amount of $\$ 10,000$ to $\$ 100,000$, from Smith \& Nephew. One of the authors (WGP) certifies that he, or a member of his immediate family, has received or may receive payments or benefits, during the study period, an amount of $\$ 100,001$ to $\$ 1,000,000$, from Zimmer Inc; and an amount of $\$ 10,000$ to $\$ 100,000$, from Biomet Inc (Warsaw, IN, USA). One of the authors (CJDV) certifies that he, or a member of his immediate family, has received or may receive payments or benefits, during the study period, an amount of $\$ 10,000$ to $\$ 100,000$, from Biomet; an amount of $\$ 10,000$ to $\$ 100,000$, from Smith \& Nephew; and an amount of less than $\$ 10,000$, from Convatec (Skillman, NJ, USA). Each remaining author (NGW, MM) certifies that he or she, or a member of his or her immediate family, has no commercial associations (eg, consultancies, stock ownership, equity interest, patent/licensing arrangements, etc) that might pose a conflict of interest in connection with the submitted article. time of surgery. Forty-six (4\%) were lost to followup and 13 died (1\%), leaving 1152 hips followed for a minimum of 90 days (mean, 2 years; range, 90 days to 7.1 years). Multivariate logistic regression was performed to identify risk factors for dislocation. The model was also tested on patients followed for a minimum 1 year to assess any difference in longer followup.

Results One hundred thirteen patients dislocated over the followup period $(9.8 \%)$. Factors that were different between patients who dislocated and those who remained stable included a history of at least one previous dislocation (odds ratio $[\mathrm{OR}]=2.673$ ), abductor deficiency $(\mathrm{OR}=$ 2.672), and Paprosky acetabulum class $(\mathrm{OR}=1.522)$.

All ICMJE Conflict of Interest Forms for authors and Clinical Orthopaedics and Related Research editors and board members are on file with the publication and can be viewed on request.

Clinical Orthopaedics and Related Research neither advocates nor endorses the use of any treatment, drug, or device. Readers are encouraged to always seek additional information, including FDA approval status, of any drug or device before clinical use.

Each author certifies that his or her institution approved the human protocol for this investigation, that all investigations were conducted in conformity with ethical principles of research, and that informed consent for participation in the study was obtained.

This work was performed at Rush University Medical Center, Chicago, IL, USA.

N. G. Wetters $(\bowtie)$, M. Moric, S. M. Sporer,

W. G. Paprosky, C. J. Della Valle

Department of Orthopaedic Surgery, Rush University

Medical Center, 1611 West Harrison Street,

Suite 300, Chicago, IL 60612, USA

e-mail: nwetters@gmail.com

T. G. Murray

Department of Orthopaedics, Cleveland Clinic,

Cleveland, $\mathrm{OH}, \mathrm{USA}$ 
Use of a constrained liner $(\mathrm{OR}=0.503)$ and increased femoral head size $(\mathrm{OR}=0.942)$ were protective against dislocation, while with longer followup a constrained liner was no longer significant.

Conclusions Dislocation remains a common problem after revision THA. Identifying these risk factors can assist in patient education and surgical planning. Recognition of these risk factors in both patient type and surgical strategy is important for the surgeon performing revision THA and for minimizing these risks.

Level of Evidence Level IV, therapeutic study. See Instructions for Authors for a complete description of levels of evidence.

\section{Introduction}

Dislocation is one of the leading causes of failure and need for rerevision after revision THA [21]. As the rate of primary THA is increasing and the population ages, the number of revision surgeries is predicted to increase in the future [14]. Identifying risk factors for this complication is important, as the identification of patients at risk can assist with preoperative patient education and management at the time of revision surgery.

Several patient- and surgery-specific risk factors have been described previously, including femoral head size, deficient abductors, nonunion of the greater trochanter, surgical approach, malposition of components, use of a liner with an elevated rim, and number of previous hip surgeries $[1,7,10,11,16]$. In the largest such study, Alberton et al. [1] reviewed 1548 revision THAs and reported an overall dislocation rate of $7.4 \%$. This study was performed, however, before the routine use of femoral head diameters larger than $32 \mathrm{~mm}$ and the authors excluded revisions for instability, tumor, and infection in their analysis. In 2011, Cogan et al. [5] evaluated 447 hips for risk factors for dislocation through an anterior approach. They found BMI was the only risk factor in their patient population. Several studies have been performed in the population of patients requiring revision for recurrent dislocation [2, 3, 19, 22]. Carter et al. [3] found previous revision surgery and smaller head sizes put these patients at risk. They also noted the use of a constrained liner is relegated to the most high-risk patients, specifically those with deficient abductors. Another study evaluating patients in the Kaiser Permanente Total Joint Registry looked at possible risk factors for dislocation for patients after both primary and revision THA [12]. Their conclusion through multivariate analysis was that previous revision surgery, higher American Society of Anesthesiologists (ASA) score, and rheumatoid arthritis were risk factors after revision THA.
The patient cohort evaluated in this article has been published previously as part of a study aimed at the question of how abduction bracing affects dislocation within 90 days after revision THA [17]. The current study reports a more in-depth evaluation of the risk factors associated with dislocation after revision THA. We are now assessing all dislocations in addition to those previously published and taking the analysis one step further by looking at multiple risk factors as opposed to a single variable as in our previous study.

We therefore (1) determined the overall risk of dislocation after revision THA in a large series of revision THAs using contemporary revision techniques, (2) identified patient-related risk factors predictive of dislocation, and (3) identified surgical variables predictive of dislocation.

\section{Patients and Methods}

Three surgeons performed 1211 revision THAs using a posterior approach (215 had concomitant extended trochanteric osteotomy) in 1050 patients between June 1, 2004, and October 31, 2010. Of the 1211 revision THAs, 13 patients $(1.1 \%)$ were deceased and $46(3.8 \%)$ were lost to followup before minimum 90 days' followup. The remaining 1152 hips in 991 patients (576 women, 415 men) had a mean age at time of surgery of 64.7 years (range, 25-95 years). These patients were followed a minimum of 90 days (mean, 2 years; range, 90 days to 7.1 years). This patient cohort of 1211 revision THAs has been reported on in a previous publication evaluating the utility of abduction bracing after revision THA [17]. No patients were recalled specifically for this study; all data were obtained from medical records.

Revision THA was defined as a surgical procedure involving exchange of the acetabular component and/or liner, femoral stem and/or modular head, or any combination thereof. Of the 1152 procedures reviewed in our cohort, the indication for revision THA was aseptic loosening in 420 (36.5\%), polyethylene wear with or without osteolysis in 223 (19.3\%), instability in 204 (17.7\%), periprosthetic joint infection in $176(15.3 \%)$, periprosthetic fracture in 55 (4.8\%), and other miscellaneous etiologies in the remaining $74(4.8 \%)$. Our standard practice includes the routine use of larger femoral head sizes $(>32 \mathrm{~mm})$, modular femoral components for patients with Paprosky Femoral Classification Type III or greater [6], and acetabular augments for instances of substantial bone loss.

Each patient was evaluated preoperatively, at 3 weeks, 6 weeks, and 3 months postoperatively, and annually thereafter for examination and radiographic followup. At each visit, standard evaluation measures, including Harris 
hip score, and plain radiographs, including AP pelvis and AP/lateral views of the affected hip, were collected [9].

Possible risk factors for dislocation were stratified as either patient or surgery specific for ease of interpretation and description. Patient-specific factors included age, sex, BMI, Paprosky femoral and acetabular classifications [6, 18] (determined from the preoperative radiographs in 1139 of 1152 hips [98.9\%]), history of at least one episode of instability before revision, number of previous hip surgeries, Charlson Comorbidity Index [4], and abductor status (classified as either intact or deficient as seen at the time of revision; deficient abductor status included nonunion of the greater trochanter or gross detachment or absence of the abductor musculature). Procedure-specific factors reviewed were acetabular cup diameter, femoral head diameter, femoral neck length, head-to-cup ratio, procedure type, use of a constrained liner, or use of an elevated rim liner. The type of procedure was separated into five categories, including isolated acetabular component revision (316, $27.4 \%$ ), isolated femoral component revision $(175,15.2 \%)$, concurrent revision of both components $(215,18.7 \%)$, modular femoral head and liner exchange (321, 27.9\%), and reimplantation THA $(125,10.8 \%)$ after treatment for periprosthetic joint infection.

Descriptive statistics for continuous and categorical variables are reported as means and SDs or counts and frequencies, respectively. We compared between stable and unstable hips normally distributed continuous variables using Student's t-test and categorical variables using a chisquare test of independence or if dichotomous using a Fisher's exact test. Identification of risk factors followed a two-step process. The first step was to identify variables that in isolation were predictive (univariate analysis), after which all variables found to be important were included in an iterative progression and evaluation of multivariate logistic regression models until the optimal, most parsimonious model was determined. Any variables missing greater than $5 \%$ of their possible data points were excluded from any analysis. Variables found to be important $(\mathrm{p}<0.10)$ in the unadjusted univariate analysis were included in a multivariate stepwise logistic regression (inclusion criteria $=0.20$, retention criteria $=0.10$ ) and reevaluated using backward elimination (retention criteria $=0.10$ ) logistic regression. Both methods (stepwise and backward elimination) provided an identical set of risk factors.

Patient factors, using univariate analysis, identified possible risk factors, including age, sex, percentage of patients undergoing at least three previous revisions, a history of instability, and deficient abductors. The same analysis identified surgical factors of cup size, head size, head-to-cup ratio, procedure type, and constrained liners as possible risk factors. Possible risk factors showing no significance were excluded.
Several important interactions were additionally evaluated, as well as different combinations of the head, cup, and head-to-cup ratio variables. Before analysis, we decided the factors of sex, age, and BMI were to be included as covariates to control for these effects and were subsequently forced into the final model. Logistic regression model assumptions and fit, as well as distributional assumptions, were evaluated for suitability. The combined set of both patient and surgical factors found to be important in the univariate analysis were used as the starting point for the stepwise and backward elimination logistic regression algorithm. We found no tested bivariate interactions to be significant and both stepwise and backward elimination methods resulted in the same final set of variables/factors. The final model fit well with a nonsignificant Hosmer and Lemeshow goodness-of-fit test (chisquare $=7.4, \mathrm{p}=0.499$ ). To evaluate the sensitivity and stability of the risk factors to our choice of followup period length, we reevaluated the final model on the subset with a minimum 1-year followup.

\section{Results}

At most recent followup, 113 of 1152 (9.8\%) hips in 113 patients had dislocated. First dislocation after revision THA occurred at a median 77 days (range, 0 days [same day as procedure] to 4.9 years) postoperatively. Our experience with extended trochanteric osteotomy showed an identical dislocation rate compared to the overall cohort, 21 of $215(9.8 \%)$. Of the 113 patients with at least one episode of instability after revision THA, 45 (40\%) were rerevised for recurrent instability. Patients undergoing revision for instability after a primary procedure dislocated at a rate of 12 of 95 (13\%) while patients undergoing revision for instability after a previous revision THA dislocated at a rate of 25 of 129 (19\%). Overall, 45 of 1152 (4\%) hips were rerevised for recurrent instability after revision THA.

After our univariate analysis, the stepwise logistic regression analysis identified sex, age, history of previous dislocation, abductor deficiency, and higher acetabular complexity as patient-specific risk factors (Table 1) and use of a constrained liner and head size as surgery-specific factors (Table 2). In addition to the risk factors identified, the unmodifiable patient demographic factor, BMI (sex and age included by default as they were identified as risk factors), was forced into the model, producing the final model (Table 3 ). The final model showed adequate accuracy with an area under the curve of $69 \%$ (Fig. 1). We reevaluated the final model on the subset with a minimum 1-year followup (Table 4) and found similar results, even with this reduced power (Fig. 2). 
Table 1. Patient-specific variables and univariate analysis of stable and unstable groups

\begin{tabular}{|c|c|c|c|}
\hline Variable & Unstable ( $\mathrm{n}=113$ hips) & Stable $(\mathrm{n}=1039$ hips $)$ & $\mathrm{p}$ value \\
\hline Age (years)* & $62(12)$ & $65(13)$ & 0.061 \\
\hline Female ( $\mathrm{n}=991$ patients) & $50 / 72(69.4 \%)$ & $526 / 919(57.2 \%)$ & 0.047 \\
\hline $\mathrm{BMI}^{*}$ & $28.3(6.2)$ & $29.1(6.8)$ & 0.235 \\
\hline Charlson Comorbidity Index $\geq 3$ & $18(15.9 \%)$ & $137(13.2 \%)$ & 0.387 \\
\hline Number of prior revisions $\geq 3$ & $28(24.8 \%)$ & $147(14.2 \%)$ & 0.005 \\
\hline History of instability & $52(46.0 \%)$ & $251(24.2 \%)$ & 0.001 \\
\hline Abductor deficiency & $19(16.8 \%)$ & $61(5.9 \%)$ & 0.001 \\
\hline Followup (years)* & $2.2(1.6)$ & $2.0(1.6)$ & 0.220 \\
\hline Paprosky femoral classification score (1-4)* & $2.4(0.5)$ & $2.3(0.5)$ & 0.098 \\
\hline Paprosky Femur Type 3A/3B/4 & $58(51.8 \%)$ & $501(48.8 \%)$ & 0.552 \\
\hline Paprosky Acetabulum Type 3A/3B & $19(17.0 \%)$ & $149(14.5 \%)$ & 0.484 \\
\hline
\end{tabular}

* Values are expressed as mean, with SD in parentheses; the remaining values are expressed as count (number of hips), with frequency in parentheses.

Table 2. Surgery-specific variables and univariate analysis of stable and unstable groups

\begin{tabular}{llll}
\hline Variable & $\begin{array}{l}\text { Unstable } \\
(\mathrm{n}=113 \\
\text { hips })\end{array}$ & $\begin{array}{l}\text { Stable } \\
(\mathrm{n}=1039 \\
\text { hips })\end{array}$ & p value \\
\hline Cup size (mm)* & $58.0(8)$ & $59.4(7)$ & 0.050 \\
Head size (mm)* & $34.2(5)$ & $36.0(5)$ & 0.001 \\
Head-to-cup ratio* & $0.60(0.08)$ & $0.62(0.07)$ & 0.008 \\
Cup revised & $53(46.9 \%)$ & $604(58.1 \%)$ & 0.027 \\
Stem revised & $40(35.4 \%)$ & $475(45.7 \%)$ & 0.037 \\
Constrained liners & $33(29.2 \%)$ & $231(22.3 \%)$ & 0.100 \\
Elevated rim & $17(15.9 \%)$ & $172(16.6 \%)$ & 0.789 \\
Modular head exchange & $111(98.2 \%)$ & $1032(99.3 \%)$ & 0.218 \\
Procedure type & & & 0.074 \\
$\quad \begin{array}{l}\text { Head/liner exchange } \\
\text { Revision of both }\end{array}$ & $41(36.3 \%)$ & $280(27.0 \%)$ & \\
$\quad$ components & $13(11.5 \%)$ & $202(19.4 \%)$ & \\
$\begin{array}{l}\text { Isolated acetabular } \\
\quad \text { revision }\end{array}$ & $32(28.3 \%)$ & $284(27.3 \%)$ & \\
$\begin{array}{l}\text { Isolated femoral revision } \\
\text { Reimplantation after }\end{array}$ & $19(16.8 \%)$ & $156(15.0 \%)$ & \\
$\quad$ revision for \\
$\quad$ periprosthetic & $8(7.1 \%)$ & $117(11.3 \%)$ & \\
$\quad$ jointinfection & & & \\
\hline
\end{tabular}

* Values are expressed as mean, with SD in parentheses; the remaining values are expressed as count (number of hips), with frequency in parentheses.

\section{Discussion}

Dislocation after revision THA remains a common problem. Despite dislocation being the most frequent complication after revision THA, risk factors for its occurrence are not completely understood. Our purposes were to determine the risk of dislocation using contemporary revision techniques (including the routine use of larger
Table 3. Risk factors in multivariate analysis for dislocation after revision THA at minimum 90 days' followup

\begin{tabular}{lllll}
\hline Variable & $\begin{array}{l}\text { Odds } \\
\text { ratio }\end{array}$ & $95 \%$ CI & & p value \\
\hline Sex (female versus male) & 1.471 & 0.940 & 2.303 & 0.091 \\
Age & 0.987 & 0.971 & 1.002 & 0.092 \\
BMI & 0.989 & 0.958 & 1.021 & 0.485 \\
History of instability & 2.673 & 1.637 & 4.365 & 0.001 \\
Abductor deficiency & 2.672 & 1.379 & 5.176 & 0.004 \\
Constrained liner & 0.503 & 0.273 & 0.925 & 0.027 \\
$\begin{array}{l}\text { Paprosky acetabulum } \\
\quad \text { classification }\end{array}$ & 1.522 & 1.000 & 2.318 & 0.050 \\
Head size & 0.942 & 0.902 & 0.983 & 0.007 \\
\hline
\end{tabular}

femoral heads $[>32 \mathrm{~mm}]$ ) and to identify surgical and patient factors that could be considered to minimize the risk of dislocation after revision THA.

Our study has several limitations. First, this was a retrospective review, and although we made an effort to identify all data points, in some cases, certain data points were missing, such as the preoperative radiographs that precluded determination of the Paprosky classification in 13 of $1152(1 \%)$. Some variables that may be interesting to evaluate, including cup version and inclination and stem offset and/or length, did not meet our criteria of less than $5 \%$ missing data points and were omitted from analysis. Second, with greater length of followup, more dislocations may occur and thus we may have underestimated the prevalence of this problem. Similarly, although we carefully reviewed each chart, some dislocations may not have been identified in our review. Finally, all procedures described were performed via a posterior approach and this may in itself be a risk factor for dislocation and may not be applicable if an alternative approach is utilized. However, most surgeons performing revisions prefer this approach 


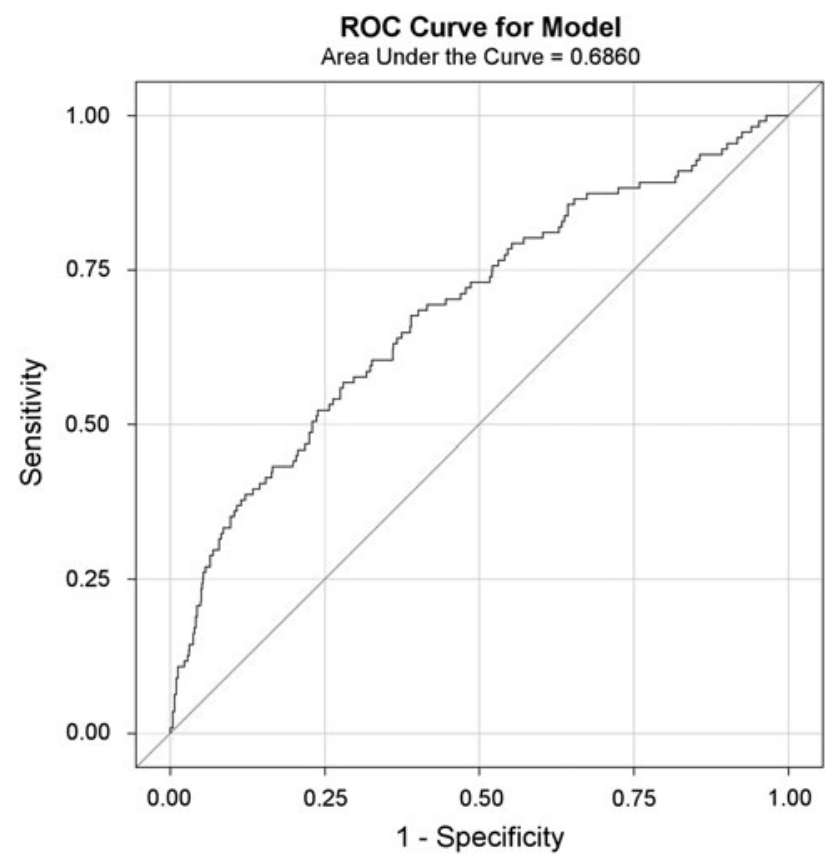

Fig. 1 In our final multivariate regression model, a receiver operating characteristic (ROC) curve demonstrates good discrimination for the interaction of risk factors for dislocation (area under the curve, $0.69)$.

Table 4. Risk factors in multivariate analysis for dislocation after revision THA at minimum 1-year followup

\begin{tabular}{lcccc}
\hline Variable & $\begin{array}{l}\text { Odds } \\
\text { ratio }\end{array}$ & $95 \%$ CI & p value \\
\hline Sex (female versus male) & 1.268 & 0.756 & 2.126 & 0.368 \\
Age & 0.990 & 0.972 & 1.009 & 0.320 \\
BMI & 0.993 & 0.972 & 1.009 & 0.320 \\
History of instability & 1.896 & 1.048 & 3.430 & 0.034 \\
Abductor deficiency & 3.215 & 1.497 & 6.908 & 0.003 \\
Constrained liner & 0.578 & 0.283 & 1.181 & 0.133 \\
Paprosky acetabulum & 1.503 & 0.922 & 2.449 & 0.102 \\
$\quad$ classification & & & & \\
Head size & 0.923 & 0.877 & 0.971 & 0.002 \\
\hline
\end{tabular}

given the greater access afforded to the posterior column of the pelvis, and thus we believe our findings are applicable to most clinical practices.

After controlling each variable using regression analysis, a history of dislocation in the operative hip and abductor deficiency were the strongest predictors of dislocation, with ORs of 2.673 and 2.672, respectively. In our practice, we have routinely used constrained liners in patients with abductor deficiency based on prior data showing large heads may not be effective for this patient subset [3,13]. This may in part explain our paradoxical finding whereby, although a higher percentage of patients
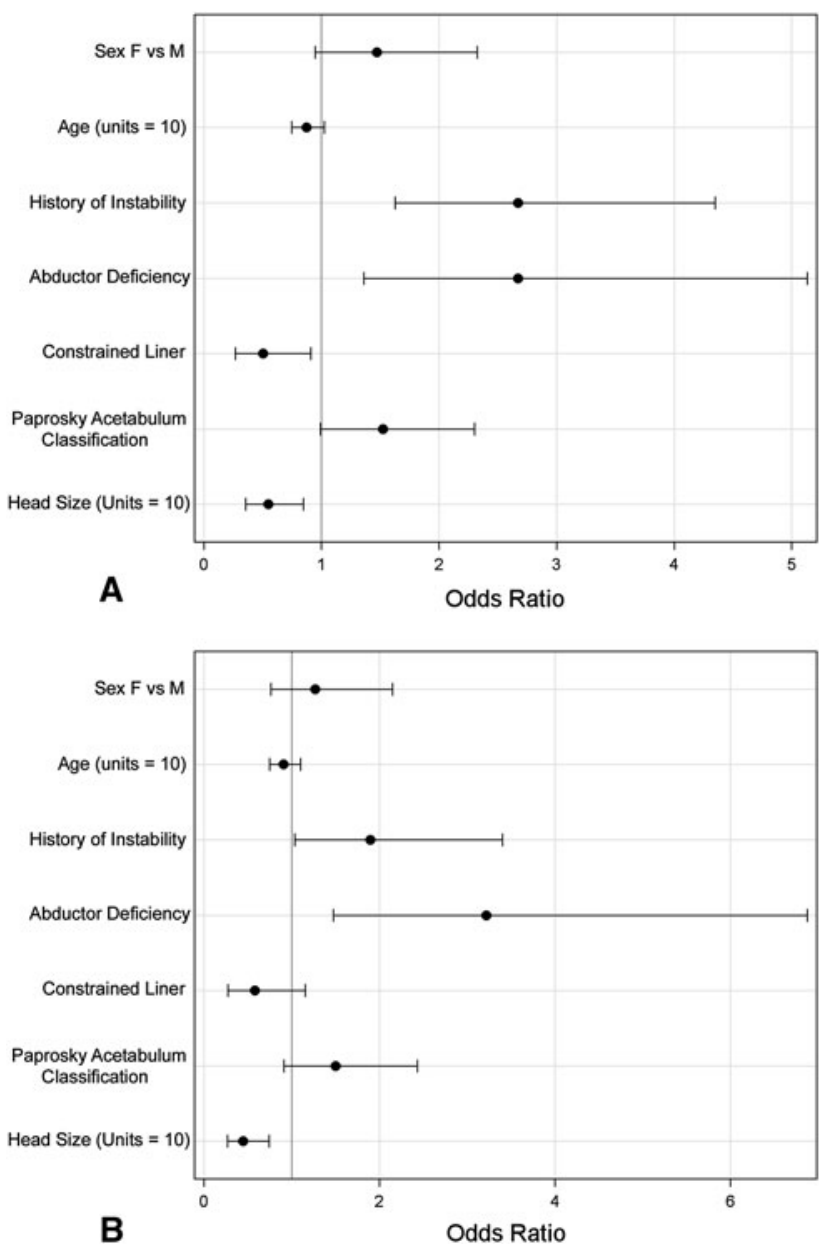

Fig. 2A-B Graphs show ORs with 95\% profile-likelihood confidence limits for patient followup at (A) minimum 90 days and (B) minimum 1 year. $\mathrm{F}=$ female; $\mathrm{M}=$ male.

in the unstable group had a constrained liner, the multivariate analysis found them to be protective against a dislocation; that is, patients in whom a constrained liner was used often had abductor deficiency and were thus at high risk and the constrained liners protected them against failure ( $\mathrm{p}=0.027$, OR $=0.503)$. When testing our model for sensitivity and stability, we lost power in our analysis, and the utility of a constrained liner was no longer significant at a followup of more than 1 year. More work is required in this area to treat this difficult patient subset.

Our dislocation rate of $9.8 \%$ is consistent with that of other studies in the literature. Currently, the dislocation rate after revision THA is between $6.6 \%$ and $21.2 \%$ [1, 3, 5, 12, 15, 23]. Alberton et al. [1] evaluated 1548 revision THAs and reported risk factors of small femoral head size, trochanteric nonunion, and elevated rim liners. Khatod et al. [12], evaluating the Kaiser Permanente database, found high ASA score, rheumatoid arthritis, and previous revision surgery were risk factors for dislocation. These are the only other studies we have found previously reporting on a 


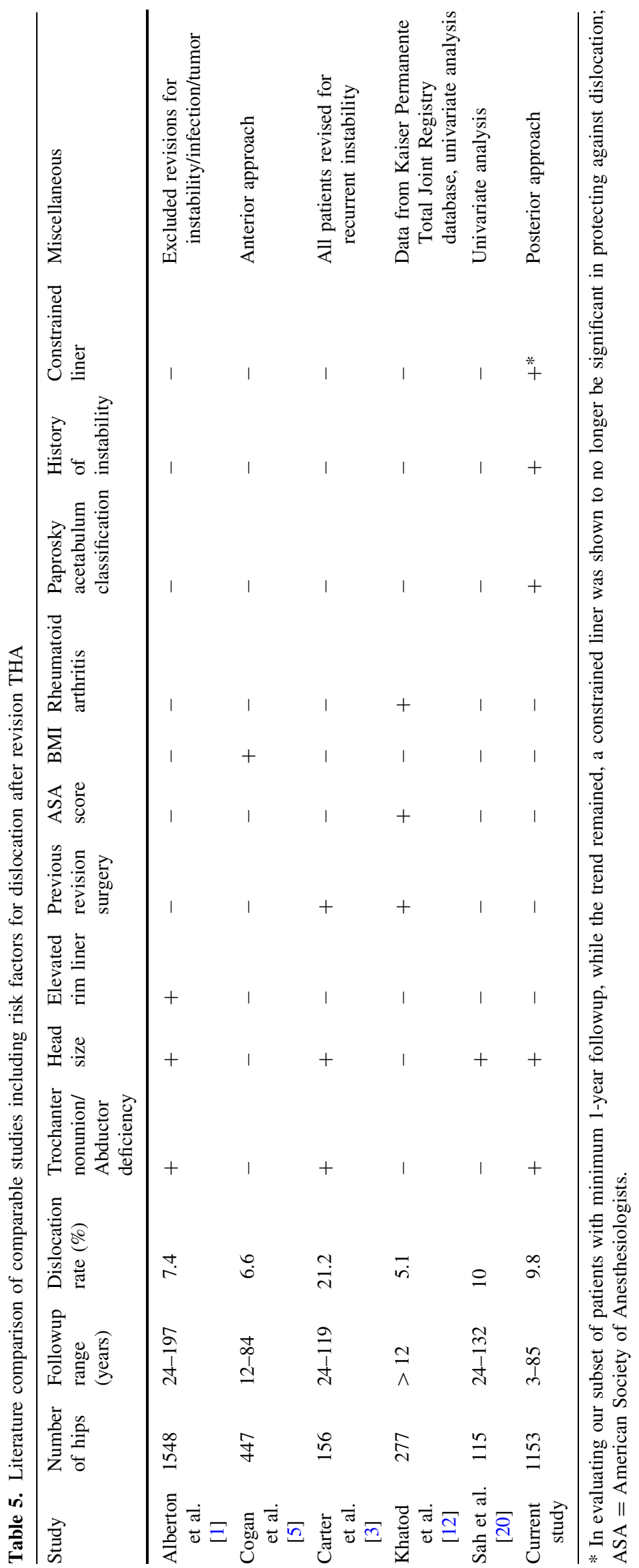


large-scale multivariate analysis. Other studies have also shown femoral head size to be a factor in the stability of the revision THA [1, 3, 8, 20]. Cogan et al. [5] evaluated patients undergoing revision THA through an anterior approach and found BMI was the only risk factor for dislocation in their patient population. Our study evaluated as many of these risk factors as possible through our stepwise logistic regression of 1211 hips and found trends in many of these same variables. We also confirmed significant risk factors from other studies, including abductor deficiency/ trochanter nonunion and small head size (Table 5).

As has been shown, using a larger femoral head diameter was also protective in our patients. Upsizing the femoral head to at least $36 \mathrm{~mm}$ during revision THA may be warranted based on this evidence and work done by Garbuz et al. [8]. They showed, in a randomized controlled trial, patients with 32-mm heads had a dislocation rate of $8.7 \%$, while using 36- and 40-mm diameter heads lowered that rate to $1.1 \%$ at a minimum followup of 2 years.

Increasing acetabular defect complexity was also a risk factor. Special attention should be paid to reproducing proper tension of the abductors and appropriately restoring the center of rotation to minimize failure by dislocation. Proper cup position may also be more difficult in these patients given the distorted anatomy.

In conclusion, our retrospective review of 1211 revision THAs showed dislocation is still a major problem despite the routine use of larger heads and other contemporary revision techniques. Patients in general should be counseled regarding the risk of this complication, and patients at higher risk (including females, younger patients, those with abductor deficiency, a history of instability, and a complex acetabular defect) should be educated regarding the presence of risk factors that make them particularly high risk for this complication. Further, the surgeon performing the revision must identify these patients and consider all options to minimize the risk of this complication. Further work is required in this area and alternative solutions, particularly for the patient with abductor deficiency, are needed.

Acknowledgments The authors thank Vamsi Kancherla, MD, for his invaluable help with this research.

\section{References}

1. Alberton GM, High WA, Morrey BF. Dislocation after revision total hip arthroplasty: an analysis of risk factors and treatment options. J Bone Joint Surg Am. 2002;84:1788-1792.

2. Biviji AA, Ezzet KA, Pulido P, Colwell CW Jr. Modular femoral head and liner exchange for the unstable total hip arthroplasty. J Arthroplasty. 2009;24:625-630.

3. Carter AH, Sheehan EC, Mortazavi SM, Purtill JJ, Sharkey PF, Parvizi J. Revision for recurrent instability: what are the predictors of failure? J Arthroplasty. 2011;26(6 suppl):46-52.
4. Charlson ME, Pompei P, Ales KL, MacKenzie CR. A new method of classifying prognostic comorbidity in longitudinal studies: development and validation. J Chronic Dis. 1987;40:373-83.

5. Cogan A, Klouche S, Mamoudy P, Sariali E. Total hip arthroplasty dislocation rate following isolated cup revision using Hueter's direct anterior approach on a fracture table. Orthop Traumatol Surg Res. 2011;97:501-505.

6. Della Valle CJ, Paprosky WG. The femur in revision total hip arthroplasty evaluation and classification. Clin Orthop Relat Res. 2004;420:55-62.

7. Ejsted R, Olsen NJ. Revision of failed total hip arthroplasty. J Bone Joint Surg Br. 1987;69:57-60.

8. Garbuz DS, Masri BA, Duncan CP, Greidanus NV, Bohm ER, Petrak MJ, Della Valle CJ, Gross AE. The Frank Stinchfield Award. Dislocation in revision THA: do large heads (36 and $40 \mathrm{~mm}$ ) result in reduced dislocation rates in a randomized clinical trial? Clin Orthop Relat Res. 2012;470:351-356.

9. Harris WH. Traumatic arthritis of the hip after dislocation and acetabular fractures: treatment by mold arthroplasty. An endresult study using a new method of result evaluation. J Bone Joint Surg Am. 1969;51:737-755.

10. Kaplan SJ, Thomas WH, Poss R. Trochanteric advancement for recurrent dislocation after total hip arthroplasty. J Arthroplasty. 1987;2:119-124.

11. Kavanagh BF, Ilstrup DM, Fitzgerald RH. Revision total hip arthroplasty. J Bone Joint Surg Am. 1985;67:517-526.

12. Khatod M, Barber T, Paxton E, Namba R, Fithian D. An analysis of the risk of hip dislocation with a contemporary total joint registry. Clin Orthop Relat Res. 2006;447:19-23.

13. Kung PL, Ries MD. Effect of femoral head size and abductors on dislocation after revision THA. Clin Orthop Relat Res. 2007; 465:170-174.

14. Kurtz S, Ong K, Lau E, Mowat F, Halpern M. Projections of primary and revision hip and knee arthroplasty in the United States from 2005 to 2030. J Bone Joint Surg Am. 2007;89: 780-785.

15. Mahomed NN, Barrett JA, Katz JN, Phillips CB, Losina E, Lew RA, Guadagnoli E, Harris WH, Poss R, Baron JA. Rates and outcomes of primary and revision total hip replacement in the United States Medicare population. J Bone Joint Surg Am. 2003; 85:27-32.

16. Morrey BF. Instability after total hip arthroplasty. Orthop Clin North Am. 1992;23:237-248.

17. Murray TG, Wetters NG, Moric M, Sporer SM, Paprosky WG, Della Valle CJ. The Use of Abduction Bracing for Early Postoperative Dislocation Prevention Following Revision Total Hip Arthroplasty. J Arthroplasty. 2012 May 17 [Epub ahead of print].

18. Paprosky WG, Perona PG, Lawrence JM. Acetabular defect classification and surgical reconstruction in revision arthroplasty: a 6-year follow-up evaluation. J Arthroplasty. 1994;9:33-44.

19. Saadat E, Diekmann G, Takemoto S, Ries MD. Is an algorithmic approach to the treatment of recurrent dislocation after THA effective? Clin Orthop Relat Res. 2012;470:482-489.

20. Sah AP, Estok DM 2nd. Dislocation rate after conversion from hip hemiarthroplasty to total hip arthroplasty. J Bone Joint Surg Am. 2008;90:506-516.

21. Springer BD, Fehring TK, Griffin WL, Odum SM, Masonis JL. Why revision total hip arthroplasty fails. Clin Orthop Relat Res. 2009;467:166-173.

22. Toomey SD, Hopper RH Jr, McAuley JP, Engh CA. Modular component exchange for treatment of recurrent dislocation of a total hip replacement in selected patients. J Bone Joint Surg Am. 2001;83:1529-1533.

23. Weiss RJ, Beckman MO, Enocson A, Schmalholz A, Stark A. Minimum 5-year follow-up of a cementless, modular, tapered stem in hip revision arthroplasty. J Arthroplasty. 2011;26:16-23. 